\title{
Deactivation and apoptosis of hepatic macrophages are involved in the development of concanavalin A-induced acute liver failure
}

\author{
QIAO YANG, YU SHI, YING YANG and ZHI CHEN \\ State Key Laboratory of Infectious Disease Diagnosis and Treatment, \\ First Affiliated Hospital, Zhejiang University, Hangzhou, Zhejiang 310003, P.R. China
}

Received February 23, 2013; Accepted June 26, 2013

DOI: $10.3892 / \mathrm{mmr} .2013 .1575$

\begin{abstract}
Activation of hepatic macrophages and systemic immunoparesis are prominent features of acute liver failure (ALF). However, the specific mechanism linking macrophage-associated inflammation and immunoparesis remains to be elucidated. The present study investigated the functional status and fate of hepatic macrophages, as well as their association with immunoparesis in ALF. Intravenous injection of concanavalin A (con A) was administered to develop a mouse model of ALF. Flow cytometry was perfomed to determine toll-like receptor 4 (TLR4) expression and the apoptotic rates of isolated hepatic macrophages in mice exposed to con A. The levels of TNF- $\alpha$, IL- 6 and IL-12p40 in serum and cell cultures were determined with enzyme-linked immunosorbent assay. TLR4 peak expression in hepatic macrophages was observed at $\sim 0.5 \mathrm{~h}$ following exposure to con $\mathrm{A}$ and rapidly decreased at 1-3 $\mathrm{h}$. The apoptotic rates of hepatic macrophages increased significantly with the exposure time of con A. The dysfunctional hepatic macrophages associated with apoptosis were observed earlier than the biochemical and histopathological changes of ALF. In addition, the production of macrophage-related inflammatory cytokines following exposure to con A in vivo or in vitro increased significantly. These observations indicated that the deactivation and apoptosis of hepatic macrophages may be a potential link between inflammation and immunoparesis in ALF.
\end{abstract}

\section{Introduction}

Acute liver failure (ALF) is a lethal syndrome characterized by the sudden cessation of hepatic function, systemic inflammatory response syndrome and multiple organ failure $(1,2)$. The

Correspondence to: Professor Zhi Chen, State Key Laboratory of Infectious Disease Diagnosis and Treatment, First Affiliated Hospital, Zhejiang University, 79 Qingchun Road, Hangzhou, Zhejiang 310003, P.R. China

E-mail: zju.zhichen@gmail.com

Key words: acute liver failure, apoptosis, inflammation, macrophages innate immune system is activated at an early stage and is crucial in the pathogenesis and the outcome of ALF. Kupffer cells, the hepatic macrophages, are key effector cells of the innate immune system within the liver and exert a pivotal 'scavenger' role over gut-derived microbial products in physiological conditions (3). Kupffer cells may be activated at the onset of ALF, express a range of sensing receptors [toll-like receptor (TLR)], release various inflammatory mediators [tumor necrosis factor- $\alpha$ (TNF- $\alpha$ ) and interleukin-6 (IL-6)] and subsequently contribute to the severe inflammatory response in liver injury (3-5). These observations have suggested a direct correlation between the functional status of hepatic macrophages and the severity of ALF.

In previous years, a new hypothesis has emerged indicating that the functional deactivation of the immune system, termed 'immunoparesis', is associated with immunosuppression and increased predisposition to infection (6). This immune paralysis is indicative of a defect in extrahepatic and intrahepatic immune components and reveals the existence of a counteractive response that protects against the initial pro-inflammatory process. It has been reported that the immune function of circulating monocytes is severely suppressed in patients with acetaminophen-induced ALF $(7,8)$. However, a few studies have investigated the profiling of functional status and fate of intrahepatic macrophages. The mechanisms associated with the role of hepatic macrophages in refractory immunoparesis during ALF are virtually unexplored.

In the present study, a mouse model of ALF was established by intravenous injection of concanavalin A (con A), which commonly serves as an animal model for studying immune-mediated ALF (9). The functional status and fate of hepatic macrophages was investigated by evaluating TLR4 expression and the apoptosis of hepatic macrophages in mice exposed to con A. In addition, the profile and degree of inflammatory mediator production with the functional status of hepatic macrophages in vivo and in vitro was assessed.

\section{Materials and methods}

Animals. Adult C57BL/6 mice (6-8 weeks old, male) were obtained from the Experimental Animal Center of Chinese Science Academy (Shanghai, China). The mice were housed in a pathogen-free environment. All of the procedures were approved by the Scientific Investigation Board of Zhejiang 
Medical College (Hangzhou, China), in accordance with the guidelines for the Care and Use of Laboratory Animals (Hangzhou, China).

Reagents. Collagenase IV, con A and protease $\mathrm{E}$ were purchased from Sigma-Aldrich (St.Louis, MO,USA). PE-Cy5-conjugated anti-mouse F4/80 antibodies, Alexa Fluor 488-conjugated anti-mouse TLR4 antibodies and the isotype control antibodies were from eBioscience Inc. (San Diego, CA, USA). The Annexin-V Apoptosis Detection kit was purchased from BD Biosciences (San Diego, CA, USA). TNF- $\alpha$, IL- 6 and IL-12p40 enzyme-linked immunosorbent assay (ELISA) kits were purchased from R\&D Systems (Minneapolis, MN, USA).

Preparation of an animal model. ALF was established in mice by intravenous injection with con A. Mice were exposed to con A $(20 \mathrm{mg} / \mathrm{kg})$ for $1,3,6,12$ and $24 \mathrm{~h}$. Mice exposed to normal saline served as the $0 \mathrm{~h}$ group (control group).

Assessment of hepatotoxicity. Hepatotoxicity was assessed by histological examination of haematoxylin and eosin (HE)-stained hepatic tissues and by detection of serum alanine aminotransferase (ALT) and aspartate transaminase (AST) levels using an Automatic Chemical Analyzer 7600-100 (Hitachi, Ltd., Tokyo, Japan). Following exposure to con A, blood was collected from the retro-orbital sinus in mice. Hepatic sections were fixed with $10 \%$ v/v neutral-buffered formalin, paraffin-embedded and cut into 3-5 $\mu \mathrm{m}$ slices. Following deparaffinisation and rehydration, the slices were stained with H\&E. Histological changes in all the specimens were assessed by two experienced pathologists.

Isolation ofliver mononuclear cells and purification of primary hepatic macrophages. Liver mononuclear cells (MNCs) were isolated by a sequential pronase/collagenase technique as described by Liu et al (10). Livers were perfused with D-Hank's solution (Invitrogen Gibco, Carlsbad, CA, USA) via the portal vein and then with HBSS (Invitrogen Gibco) containing $0.01 \% \mathrm{w} / \mathrm{v}$ protease E (Sigma-Aldrich) and $0.05 \% \mathrm{w} / \mathrm{v}$ collagenase IV (Sigma-Aldrich). The homogenate of liver tissue was filtered through a 200 -gauge mesh. Hepatocytes were removed by centrifugation at $50 \mathrm{x} \mathrm{g}$ for $5 \mathrm{~min}$. Supernatant containing MNCs was isolated by density gradient centrifugation with Percoll (30\% v/v over 60\% v/v; Pharmacia, Uppsala, Sweden) at $800 \mathrm{x} \mathrm{g}$ for $20 \mathrm{~min}$. In the in vitro experiments, purification of hepatic macrophages was performed by the selective adherence method (11). The non-adherent cells were removed $4 \mathrm{~h}$ later by extensive washing with medium. The cells were incubated in 24-well plates at a density of $1.0 \times 10^{5} \mathrm{cells} / \mathrm{well}$ in DMEM supplemented with $10 \% \mathrm{v} / \mathrm{v}$ FBS, $100 \mathrm{U} / \mathrm{ml}$ penicillin and $100 \mu \mathrm{g}$ streptomycin at $37^{\circ} \mathrm{C}$ in $5 \% \mathrm{CO}_{2}$. The purity of hepatic macrophages bound by $\mathrm{F} 4 / 80+$ antibodies was $~ 88 \%$. Cell viability measured by the trypan blue exclusion assay was $\geq 95 \%$.

Flow cytometry to determine the expression of TLR 4 on F4/80+ hepatic macrophages. Following incubation with Fc-blocker, hepatic MNCs were incubated with PE-Cy5-conjugated F4/80 antibodies and Alexa Fluor 488-conjugated TLR4 antibodies at $4^{\circ} \mathrm{C}$ in the dark for $15 \mathrm{~min}$ and washed once with PBS.
Isotype-matched antibodies were used as controls to eliminate non-specific binding. The frequency of TLR4+ hepatic macrophages was characterized by gating on F4/80+ cells using flow cytometric analysis. A minimum of $1 \times 10^{5}$ cells was measured by Beckman Coulter flow cytometry (FC500 MPL; Beckman Coulter, Inc. Brea, CA, USA) and data were analyzed by CXP software.

Determination of apoptosis of hepatic macrophages. Hepatic macrophages were identified using the macrophage marker, F4/80. Hepatic MNCs were stained with PE-Cy5-conjugated F4/80 antibodies. The apoptotic rates of hepatic macrophages exposed to con A in vivo and in vitro were measured using a commercial Annexin-V/PI assay according to the manufacturer's instructions by flow cytometry.

Evaluation of the cytokine levels in mouse serum and culture supernatant. Serum and culture supernatant levels of TNF- $\alpha$, IL-6 and IL-12p40 were quantified by ELISA kits from R\&D Systems. Absorbance was measured at $450 \mathrm{~nm}$ using a microtiter plate reader (Bio-Rad).

Statistical analysis. Data were expressed as mean \pm SD. In vitro experiments were repeated a minimum of three times. SPSS statistical software 13.0 for Windows was used for data analysis (SPSS Inc., Chicago, IL, USA). Data were compared using t-tests or one-way ANOVA, followed by the LSD post-hoc test (equal variances) or Dunnett's T3 post-hoc test (unequal variances). $\mathrm{P}<0.05$ was considered to indicate a statistically significant difference.

\section{Results}

Con A induces acute liver failure. Con A induced ALF in mice with massive necroinflammatory foci within $12 \mathrm{~h}$ and a high mortality within $24 \mathrm{~h}$ (Fig. 1). Table I shows that ALT levels in 3-24 h groups increased significantly compared with 0 or $1 \mathrm{~h}$ groups $(\mathrm{P}<0.05)$ and that there was a time-effect correlation. The AST levels in the 6-24 h groups were significantly higher than those in the $0-3 \mathrm{~h}$ groups $(\mathrm{P}<0.05)$ and there was a significant difference between the 12 and $24 \mathrm{~h}$ groups $(\mathrm{P}<0.05)$.

Activated status of hepatic macrophages in the development of $A L F$. The activated status of hepatic macrophages was verified with TLR4 expression which was previously used to assess macrophage activation $(2,4)$. Fig. 2 shows that the peak of TLR4 levels occurred $\sim 0.5 \mathrm{~h}$ following exposure to Con A, which rapidly decreased at $1 \mathrm{~h}(\mathrm{P}<0.05)$ and there was a significant difference between the 1 and $3 \mathrm{~h}$ groups $(\mathrm{P}<0.05)$.

Hepatic macrophages in livers of mice exposed to con A undergo apoptosis. Fig. 3 shows that the apoptotic rates of F4/80+ hepatic macrophages in the 1 and $3 \mathrm{~h}$ groups were significantly higher than that in the $0 \mathrm{~h}$ group $(\mathrm{P}<0.05)$ and there was a significant difference between the 0.5 and $3 \mathrm{~h}$ groups $(\mathrm{P}<0.05)$.

Levels of serum cytokine in mice exposed to con A. Fig. 4 demonstrates that TNF- $\alpha$ levels in the 3-12 $\mathrm{h}$ groups increased significantly when compared with the 0 and $1 \mathrm{~h}$ 
Table I. Levels of serum ALT and AST (U/l) in mice exposed to con A in vivo (mean $\pm \mathrm{SD})$.

\begin{tabular}{lcccccc}
\hline Groups & $0 \mathrm{~h}$ & $1 \mathrm{~h}$ & $3 \mathrm{~h}$ & $6 \mathrm{~h}$ & $12 \mathrm{~h}$ & $24 \mathrm{~h}$ \\
\hline ALT & $108.0 \pm 35.6$ & $176.0 \pm 57.3$ & $751.0 \pm 82.2^{\mathrm{a}, \mathrm{b}}$ & $4,924.0 \pm 1089.8^{\mathrm{a}-\mathrm{c}}$ & $11,884 \pm 3234.9^{\mathrm{a}-\mathrm{c}}$ & $21,786 \pm 3840.6^{\mathrm{a}-\mathrm{e}}$ \\
AST & $168.0 \pm 24.9$ & $232.0 \pm 68.7$ & $528.8 \pm 222.4$ & $3,946.0 \pm 1634.9^{\mathrm{a}, \mathrm{b}}$ & $10,086 \pm 1622.9^{\mathrm{a}-\mathrm{d}}$ & $16,638 \pm 2675.0^{\mathrm{a}-\mathrm{e}}$
\end{tabular}

Data from five mice in each group were analyzed using ANOVA. ${ }^{\mathrm{a}} \mathrm{P}<0.05$, vs. $0 \mathrm{~h}$; ${ }^{\mathrm{b}} \mathrm{P}<0.05$, vs $1 \mathrm{~h}$; ${ }^{\mathrm{c}} \mathrm{P}<0.05$, vs $3 \mathrm{~h}$; ${ }^{\mathrm{d}} \mathrm{P}<0.05$, vs $6 \mathrm{~h}$; ${ }^{\mathrm{e}} \mathrm{P}<0.05$, vs $12 \mathrm{~h}$. ALT, alanine aminotransferase; AST, aspartate aminotransferase; con A, concanavalin A.

A
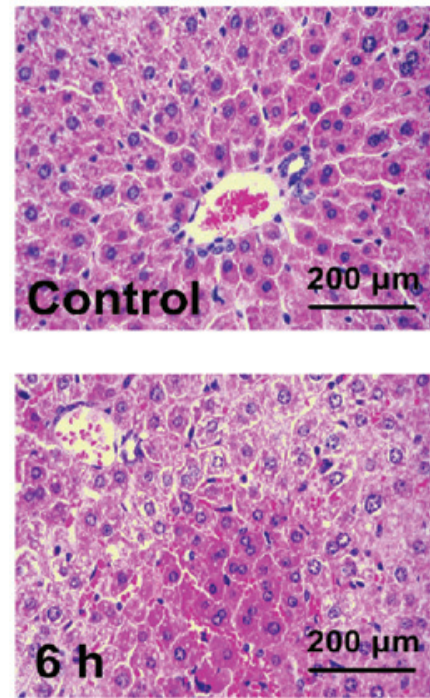
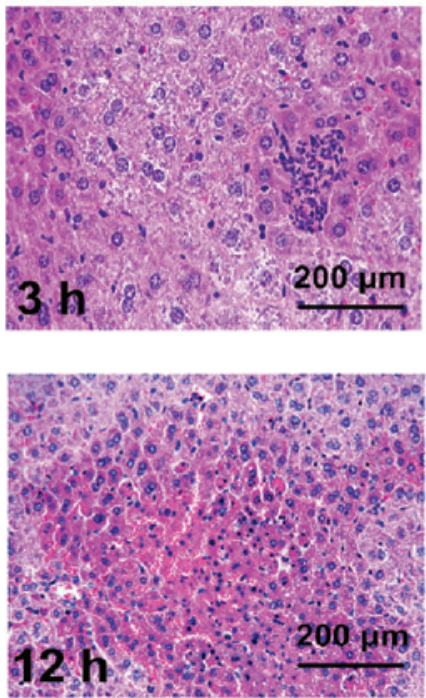

B

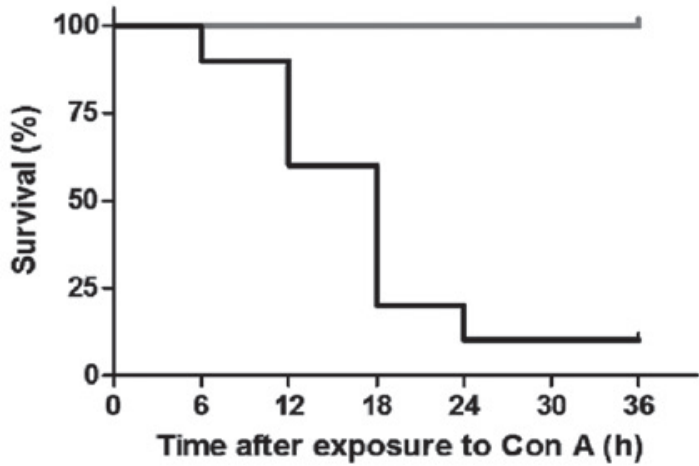

Figure 1. Liver injury characteristics of mice exposed to $20 \mathrm{mg} / \mathrm{kg}$ con A. (A) Histological analysis of liver tissue by H\&E staining. The hepatic sections from mice exposed to con A or control mice were formalin-fixed, paraffin-embedded and cut into 3-5 $\mu \mathrm{m}$ slices. Following deparaffinisation and rehydration, the slices were stained with H\&E. Representative images of liver sections from six animals in each group are presented (original magnification, x200). (B) Different groups of mice were observed for their survival rate following con A or normal saline treatment. C57BL/6 mice were injected with con A (20 mg/ $\mathrm{kg}$ ) or normal saline and their survival rate was observed. Control: mice $(\mathrm{n}=0)$ were exposed to normal saline; con A: mice $(\mathrm{n}=10)$ were exposed to con A. con A, concanavalin A; H\&E, haematoxylin and eosin.

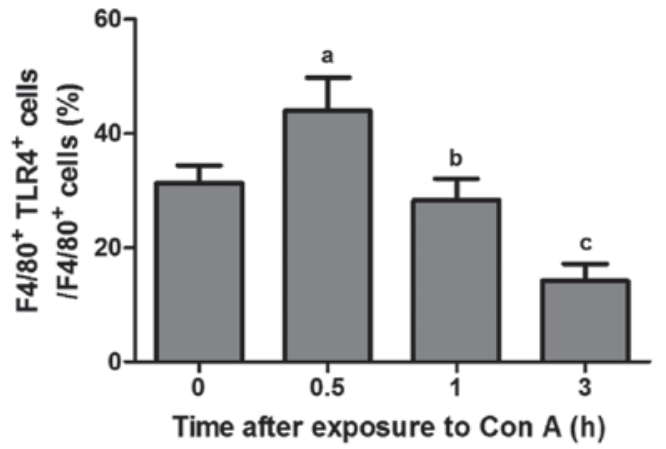

Figure 2. Expression profiling of TLR4 in F4/80+ cells in mice exposed to con A. Hepatic MNCs from mice exposed to con A or control were stained with anti-F4/80 and anti-TLR4 antibodies and the frequency of TLR4+ hepatic macrophages was characterized by gating on F4/80+ cells by flow cytometry. A minimum of $1 \times 10^{5}$ cells were analyzed. ${ }^{a} \mathrm{P}<0.05 \mathrm{vs} .0 \mathrm{~h} ;{ }^{b} \mathrm{P}<0.05$ vs. $0.5 \mathrm{~h} ;{ }^{\mathrm{C}} \mathrm{P}<0.05$ vs. $1 \mathrm{~h}$. Data were analyzed using the Student's t-test (each group, $\mathrm{n}=6$ ). Con A, concanavalin A; TLR4, toll-like receptor 4.

groups $(\mathrm{P}<0.05)$. In addition, TNF- $\alpha$ levels in $6-12 \mathrm{~h}$ groups were significantly higher than those in the $3 \mathrm{~h}$ group $(\mathrm{P}<0.05)$. IL-6 levels in all the exposure groups increased significantly compared with the $0 \mathrm{~h}$ group $(\mathrm{P}<0.05)$. IL-6 serum levels

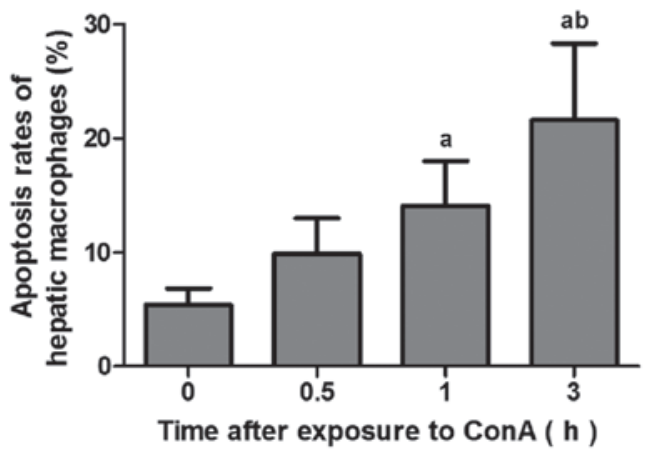

Figure 3. Apoptotic rates of $\mathrm{F} 4 / 80+$ hepatic macrophages in mice exposed to con A for 0.5-3 h. Hepatic MNCs from mice exposed to con A or control mice were stained with anti-F4/80 antibody and Annexin-V and the apoptotic rates of hepatic macrophages were characterized by gating on F4/80+ cells using flow cytometric analysis. ${ }^{a} \mathrm{P}<0.05$ vs. $0 \mathrm{~h} ;{ }^{\mathrm{b}} \mathrm{P}<0.05$ vs. $0.5 \mathrm{~h}$. Data from six mice in each group were analyzed using ANOVA. Con A, concanavalin A.

peaked at $6 \mathrm{~h}$ following con A exposure and significant differences were identified between the 6 and $12 \mathrm{~h}$ groups $(\mathrm{P}<0.05)$. The IL-12p40 levels in the $3-12 \mathrm{~h}$ groups also increased significantly, when compared with the $0-1$ h groups $(\mathrm{P}<0.05)$. 

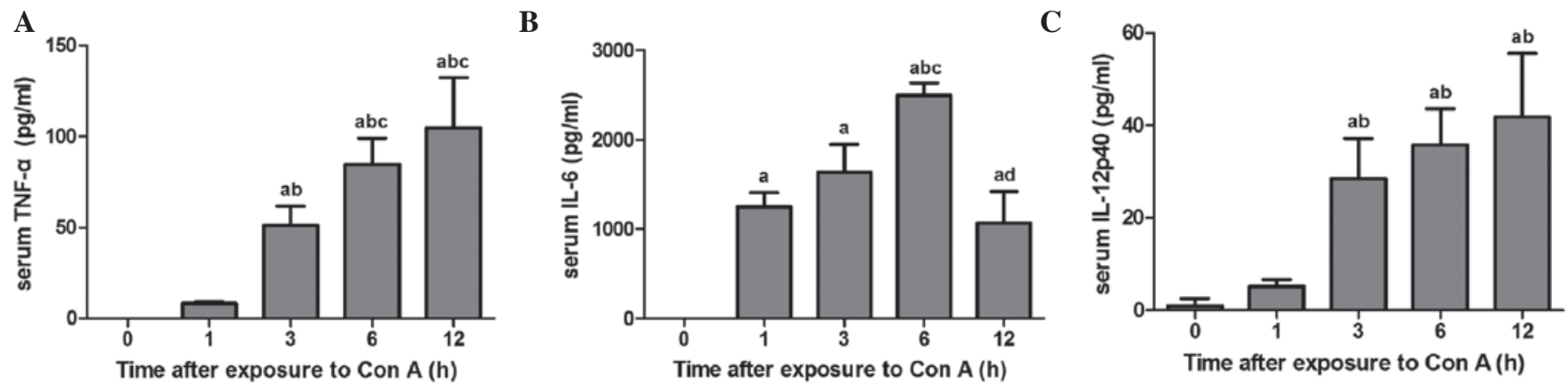

Figure 4. (A) TNF- $\alpha$, (B) IL-6 and (C) IL-12p40 levels in serum of mice exposed to ? con A. Blood was collected from the retro-orbital sinus and allowed to clot at $4{ }^{\circ} \mathrm{C}$ overnight. Serum levels of TNF- $\alpha$, IL-6 and IL-12p40 were quantified by ELISA. ${ }^{\mathrm{a}} \mathrm{P}<0.05$, vs. 0 h; ${ }^{\mathrm{b}} \mathrm{P}<0.05$, vs. $1 \mathrm{~h} ;{ }^{\mathrm{c}} \mathrm{P}<0.05$, vs. $3 \mathrm{~h}$; ${ }^{\mathrm{d}} \mathrm{P}<0.05$. vs. $6 \mathrm{~h}$. Data from three mice in each group were analyzed using ANOVA. TNF- $\alpha$, tumor necrosis factor- $\alpha$.
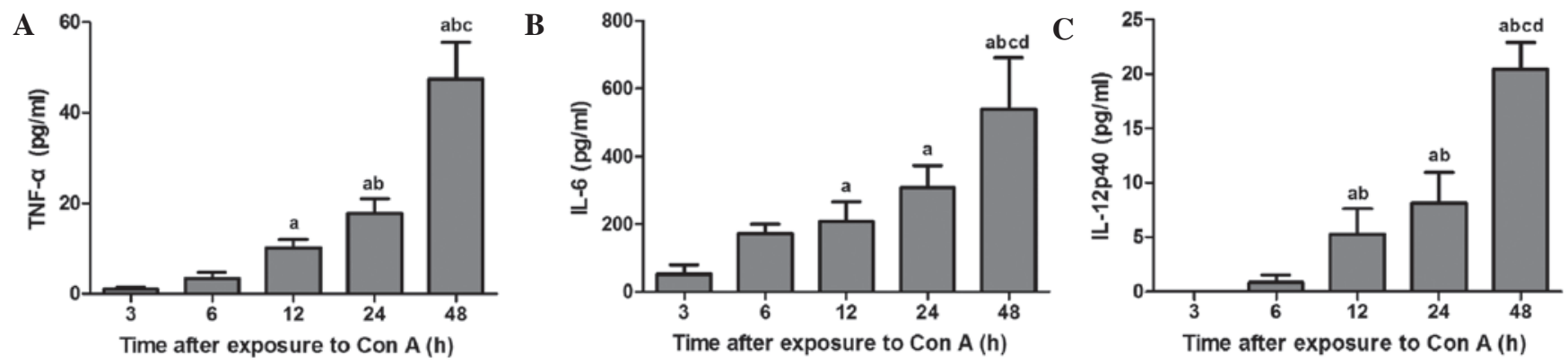

Figure 5. (A) TNF- $\alpha$, (B) IL-6 and (C) IL-12p40 levels in supernatants of hepatic macrophages exposed to $10 \mu \mathrm{g} / \mathrm{ml}$ con A in vitro. Primary hepatic macrophages were isolated from healthy mice and purified by extensive washing with medium. Cells were exposed to con A for $48 \mathrm{~h}$. Serum levels of TNF- $\alpha$, IL-6 and IL-12p40 in the supernatants were quantified by ELISA kits. ${ }^{a} \mathrm{P}<0.05$, vs. $3 \mathrm{~h} ;{ }^{b} \mathrm{P}<0.05$, vs. $6 \mathrm{~h} ;{ }^{\mathrm{c}} \mathrm{P}<0.05$, vs. $12 \mathrm{~h} ;{ }^{\mathrm{d}} \mathrm{P}<0.05$, vs. $24 \mathrm{~h}$. Data from three independent experiments were analyzed using ANOVA. TNF- $\alpha$, tumor necrosis factor- $\alpha$; con A, concanavalin A.

Hepatic marophages undergo apoptosis following exposure to con $A$ in vitro. When the exposure doses were higher than $20 \mu \mathrm{g} / \mathrm{ml}$ for $3 \mathrm{~h}, 5 \mu \mathrm{g} / \mathrm{ml}$ for $6 \mathrm{~h}$ and $10 \mu \mathrm{g} / \mathrm{ml}$ for 12 or $24 \mathrm{~h}$, the early apoptotic rates of exposure groups were significantly higher than those of the control groups $(\mathrm{P}<0.05)$ and increased in a dose-dependent manner. When the exposure doses were higher than $20 \mu \mathrm{g} / \mathrm{ml}$ for 3 or $6 \mathrm{~h}$ or $10 \mu \mathrm{g} / \mathrm{ml}$ for 12 or $24 \mathrm{~h}$, the proportion of late apoptotic and necrotic cells of exposure groups was significantly higher than those of the control groups $(\mathrm{P}<0.05)$ and increased in a dose-dependent manner (Table II). These observations indicate that the early and late apoptotic or necrotic rates of hepatic macrophages increased in a con A dose-dependent manner and apoptosis of hepatic macrophages exposed to con A may be involved in con A-induced ALF.

Hepatic macrophages release cytokines following exposure to con A. Fig. 5 shows the levels of the cytokines, TNF- $\alpha$, IL-6 and IL-12p40, in hepatic macrophage culture exposed to con $\mathrm{A}(10 \mu \mathrm{g} / \mathrm{ml})$. TNF- $\alpha$ levels in hepatic macrophage culture exposed to con A for 12,24 and $48 \mathrm{~h}$ were significantly higher than those in the $3 \mathrm{~h}$ group $(\mathrm{P}<0.05)$. Maximum levels of TNF- $\alpha$ were observed at $48 \mathrm{~h}$ following exposure of hepatic macrophages to con A. IL-6 levels in the 12-48 $\mathrm{h}$ groups increased significantly compared with the $3 \mathrm{~h}$ group $(\mathrm{P}<0.05)$. IL-6 levels in the $48 \mathrm{~h}$ group were significantly higher than those in the $6-24 \mathrm{~h}$ groups $(\mathrm{P}<0.05)$. IL-12p40 levels in the 3-6 h group were significantly lower compared with those in the 12-48 $\mathrm{h}$ groups $(\mathrm{P}<0.05)$. Levels of IL-12p40 at $48 \mathrm{~h}$ following exposure of hepatic macrophages to con A were the highest of all the time points $(\mathrm{P}<0.05)$.

\section{Discussion}

The massive inflammatory infiltration of hepatic macrophages in the initial phase of ALF emphasizes the important role of these cells in the pathogenesis of $\operatorname{ALF}(3,4)$. It has been hypothesized that macrophages are activated by various stimuli through TLR expression to initiate the pro-inflammatory response, promoting tissue injury. TLR4 has been used to identify macrophage activation $(2,4,12)$. The present study has confirmed that the expression of TLR4 in hepatic macrophages increased in the initial phase $(0.5 \mathrm{~h})$ of con A-induced ALF. However, it was also observed that TLR4 expression in hepatic macrophages decreased rapidly at $1 \mathrm{~h}$ following con A exposure. These observations indicate that the initial activated status of hepatic macrophages is followed by subsequent immunosuppression during the development of ALF.

Previous studies have demonstrated that dysfunction of monocytes has been observed in patients with acute-on-chronic liver failure and the apoptosis of hepatic macrophages is involved in liver inflammation and fibrosis $(7,10,13)$. However, the apoptosis of hepatic macrophages in ALF has been largely ignored and is rarely reported. To determine the fate of the deactivated hepatic macrophages, apoptosis of hepatic macro- 
phages was further investigated. In vivo experiments revealed that the apoptotic rates of hepatic macrophages and the levels of the macrophage-related pro-inflammatory cytokines, TNF- $\alpha$, IL-6 and IL-12p40, in serum significantly increased with con A exposure time. Apoptosis associated with TLR4 expression profiling in hepatic macrophages indicates the complexity between cell activation and apoptosis. Fig. 1 and Table I reveal the marked necrotic foci and enhanced serum levels of ALT and AST in mice exposed to con A at $~ 6-24 \mathrm{~h}$, whereas the functional switch and apoptosis of hepatic macrophages was observed at 0.5-1 h following con A exposure. Functional macrophage deactivation and apoptosis of hepatic macrophages occurred prior to biochemical and pathological changes, which further indicated that apoptosis of hepatic macrophages is important in the subsequent development of hepatitis.

ALF is characterized by sudden and persistent cellular apoptosis. When a large amount of the early apoptotic cells may not be scavenged and eliminated immediately, late apoptotic and necrotic cells inevitably occur, which may passively release inflammatory mediators further and lead to the exacerbation of liver damage (14). Thus, it is necessary to observe whether apoptotic hepatic macrophages may also release pro-inflammatory cytokines. Table II shows that con A induces early cell apoptosis, late apoptosis or necrosis. In addition, in vitro experiments in the present study revealed that apoptotic or necrotic hepatic macrophages also release a range of pro-inflammatory cytokines, TNF- $\alpha$, IL-6 and IL-12p40, which are associated with hepatocyte injury, respiratory burst and adaptive immune response (15-19), suggesting a link between inflammation, cell apoptosis and immunoparesis in the development of ALF. However, the kinetic changes of the three cytokine levels in supernatants were slightly different from those in the serum of mice exposed to con A. It has been hypothesized that the serum cytokines were not only released from the apoptotic hepatic macrophages but also from other cells $(9,20-22)$. These observations indicate that pro-inflammatory cytokines, TNF- $\alpha$, IL-6 and IL-12p40, released by apoptotic or necrotic hepatic macrophages may contribute to a further pathophysiological response in con A-induced ALF.

In conclusion, the present in vivo studies measuring the expression of TLR4 on hepatic macrophages and the apoptosis of hepatic macrophages, in combination with the ex vivo experiments, demonstrate that deactivation and apoptosis of hepatic macrophages is involved in the pathogenesis of con A-induced ALF. These observations are likely to improve our understanding of the essential roles of hepatic macrophages in the progression of ALF, as well as explain the potential leakage among inflammation, apoptosis and immunoparalysis in ALF and emphasize the requirement for the development of therapeutic manipulations to inhibit overactivated hepatic macrophages and apoptosis for the treatment of ALF.

\section{Acknowledgements}

The present study was supported by the $12-5$ State $\mathrm{S}$ and T Projects of China (no. 2012ZX10002007) and the National Natural Science Foundation of China (no. 81000730). 


\section{References}

1. Rolando N, Wade J, Davalos M, Wendon J, Philpott-Howard J and Williams R: The systemic inflammatory response syndrome in acute liver failure. Hepatology 32: 734-739, 2000.

2. Verbeke L, Nevens F and Laleman W: Bench-to-beside review: acute-on-chronic liver failure - linking the gut, liver and systemic circulation. Crit Care 15: 233, 2011.

3. Yang Q, Shi Y, He J and Chen Z: The evolving story of macrophages in acute liver failure. Immunol Lett 147: 1-9, 2012.

4. Laskin DL: Macrophages and inflammatory mediators in chemical toxicity: a battle of forces. Chem Res Toxicol 22: 1376-1385, 2009

5. Zimmermann HW, Trautwein C and Tacke F: Functional role of monocytes and macrophages for the inflammatory response in acute liver injury. Front Physiol 3: 56, 2012.

6. Wasmuth HE, Kunz D, Yagmur E, et al: Patients with acute on chronic liver failure display 'sepsis-like' immune paralysis. J Hepatol 42: 195-201, 2005.

7. Antoniades CG, Berry PA, Davies ET, Hussain M, Bernal W, Vergani D and Wendon J: Reduced monocyte HLA-DR expression: a novel biomarker of disease severity and outcome in acetaminophen-induced acute liver failure. Hepatology 44 : 34-43, 2006.

8. Antoniades CG, Berry PA, Wendon JA and Vergani D: The importance of immune dysfunction in determining outcome in acute liver failure. J Hepatol 49: 845-861, 2008.

9. Tiegs G, Hentschel J and Wendel A: A T cell-dependent experimental liver injury in mice inducible by concanavalin A J Clin Invest 90: 196-203, 1992.

10. Liu C, Tao Q, Sun M, et al: Kupffer cells are associated with apoptosis, inflammation and fibrotic effects in hepatic fibrosis in rats. Lab Invest 90: 1805-1816, 2010.

11. Canbay A, Feldstein AE, Higuchi H, Werneburg N, Grambihler A, Bronk SF and Gores GJ: Kupffer cell engulfment of apoptotic bodies stimulates death ligand and cytokine expression. Hepatology 38: 1188-1198, 2003.
12. Kaisho $\mathrm{T}$ and Akira S: Toll-like receptors and their signaling mechanism in innate immunity. Acta Odontol Scand 59: 124-130, 2001.

13. Xing T, Li L, Cao H and Huang J: Altered immune function of monocytes in different stages of patients with acute on chronic liver failure. Clin Exp Immunol 147: 184-188, 2007.

14. Savill J, Dransfield I, Gregory C and Haslett C: A blast from the past: clearance of apoptotic cells regulates immune responses. Nat Rev Immunol 2: 965-975, 2002.

15. Streetz K, Leifeld L, Grundmann D, et al: Tumor necrosis factor alpha in the pathogenesis of human and murine fulminant hepatic failure. Gastroenterology 119: 446-460, 2000.

16. Chastre A, Bélanger M, Beauchesne E, Nguyen BN, Desjardins P and Butterworth RF: Inflammatory cascades driven by tumor necrosis factor-alpha play a major role in the progression of acute liver failure and its neurological complications. PLoS One 7: e49670, 2012.

17. Bettelli E, Carrier Y, Gao W, et al: Reciprocal developmental pathways for the generation of pathogenic effector TH17 and regulatory T cells. Nature 441: 235-238, 2006.

18. Sekiyama KD, Yoshiba M and Thomson AW: Circulating proinflammatory cytokines (IL-1 beta, TNF-alpha and IL-6) and IL-1 receptor antagonist (IL-1Ra) in fulminant hepatic failure and acute hepatitis. Clin Exp Immunol 98: 71-77, 1994.

19. Cooper AM and Khader SA: IL-12p40: an inherently agonistic cytokine. Trends Immunol 28: 33-38, 2007.

20. Knolle PA, Gerken G, Loser E, et al: Role of sinusoidal endothelial cells of the liver in concanavalin A-induced hepatic injury in mice. Hepatology 24: 824-829, 1996.

21. Gantner F, Leist M, Küsters S, Vogt K, Volk HD and Tiegs G $\mathrm{T}$ cell stimulus-induced crosstalk between lymphocytes and liver macrophages results in augmented cytokine release. Exp Cell Res 229: 137-146, 1996.

22. Hatada S, Ohta T, Shiratsuchi Y, Hatano M and Kobayashi Y: A novel accessory role of neutrophils in concanavalin A-induced hepatitis. Cell Immunol 233: 23-29, 2005. 